\title{
The dynamics of theories of economic growth: An impact of Unified Growth Theory ${ }^{1}$
}

\section{Pawet Kawalec $^{2}$}

\begin{abstract}
The aim of this paper is to examine a complex pattern of mutual interdependence between Unified Growth Theory (subroutine) and the evolution of the entire field of economic growth theories (main routine) from a philosophical and methodological perspective. The analysis utilises the recently introduced concept of research routine (and respectively, subroutine) aimed at an explanation of the evolution of scientific research. The study identifies the influence of the subroutine (and its specific concept of demographic transition) on the core concepts of the main routine: human capital, population growth and learning. The results are based on network analyses of extensive bibliometric evidence from Scopus and the Web of Knowledge.
\end{abstract}

Keywords: demographic transition, human capital, fertility rate, Oded Galor, research routine, philosophy of science, methodology.

JEL codes: B40, B52, C18, O40.

\section{Introduction}

The paper is an attempt to understand a complex pattern of mutual interdependence between Unified Growth Theory (a subroutine) and the evolution of the entire field of economic growth theories (the main routine) from a philosophical and methodological perspective. Traditionally this kind of problem was conceptualized in philosophy in terms of scientific progress. A recent classification of the pertinent approaches by Emiliano Ippoliti (2017) distinguishes three broad categories: deductivist, cognitivist and evolutionary. Deductivism, originating with logical empiricism and epitomized with Karl Popper's Logic of scientific discovery assumes that there is an inherent logic underlying the contingency of details of the historical progress in a given field of research. This logic is framed by the rules of deduction and thus can be represented by

\footnotetext{
${ }^{1}$ Article received 10 February 2020, accepted 8 June 2020.

${ }^{2}$ Institute of Philosophy, John Paul II Catholic University of Lublin, Al. Racławickie 14, 20-950 Lublin, Poland, pawel.kawalec@kul.pl, ORCID: https://orcid.org/0000-0001-7618-8298.
} 
the modern mathematical logic that has occupied the minds of philosophers since the beginning of the 20th century. Apparently the main limitation of this approach is due to the fact that deductive logic as an non-ampliative form of reasoning could not explain how new hypotheses originate and how they may lead to hitherto unknown conclusions.

The cognitivist approach considers scientific progress to be a result of the application of ordinary human cognitive skills to solve research problems. In particular it claims that the ordinary inferential rules can be explicitly articulated and then implemented in algorithms such as BACON which was supposedly capable of re-discovering of Kepler's laws. However while BACON misses out important skills such as the ability to determine the relevant variables and data it turns out that, at best, it is only capable-similarly to deductive logic - to reconstruct past discoveries. Moreover, this approach ignores all kinds of contingencies that may influence the actual trajectory of scientific discoveries.

The evolutionary approach, in contrast, adopts the view that at its core the generation of new scientific knowledge is governed by an evolutionary mechanism akin to blind variation and selective retention. One upshot of this approach is that the idea of a blind combinatorial mechanism underlying scientific progress would undermine the intentionality of the latter and of the apparently purposeful efforts of scientists. Besides it seems to ignore the role of external impulses such as unexpected changes in the observed phenomena, for instance economic crises or natural disasters, that apparently increase the intensity of research efforts concerned with them.

A different and perhaps more pertinent way to present the different approaches to scientific progress is by focusing on their ontological assumptions by distinguishing between particularist vs processualist approaches. Particularists tend to focus on a relatively isolated achievement, such as a highly cited publication that can be associated with advancing the relevant field of research. Very often it is dubbed "scientific discovery" or "watershed". Apart from the micro-scale ontological units such as a journal article some particularists try to identify large-scale (macro) ontological units such as paradigms that would frame the given discipline as a whole. Thomas Kuhn's idea of incommensurable paradigms (typical macro-scale units) is perhaps the most debatable particularist proposal (Devlin \& Bokulich, 2015). Somewhat surprisingly a similar particularist predilection marks the (micro-level) scientometric approach of Derek de Solla Price (1951, 1965; Andersen \& Hammarfelt, 2011). Their logistic growth curves, notwithstanding the appearance to the contrary, are generated manually by slicing the datasets into isolated fitting patterns which are then formed into a growth curve.

The concept of research routine (a meso-level unit) outlined in the next section represents a pattern of research practices of a scientific community (in the sense of Robert Merton's “invisible college”) which share a common symbolic 
representation (such as a model or theory) and focuses on the evolutionary continuity of progress in science (Kawalec, 2018a, 2018b, 2020). A new routine would typically be initiated by a small group of scholars, for instance a research team in a laboratory, who steadily work out a new concept, model or theory, in a series of research processes-each of which enacts the routine to generate new hypotheses and thereby modifying it to a lesser or larger extent (by instituting new breakthrough concepts, novel links with the established body of scientific knowledge or applications to practical problems). With time this routine diffuses within the scientific community by attracting new talents and eventually by inaugurating new institutional forms (such as a topical conference, dedicated journal, association, chair, institute, or new sub-discipline). ${ }^{3}$ As the dynamics of research routine are manifested by the evolution of the (multi-dimensional) network as a whole the former can, at least partially, be re-constructed bottom-up from bibliometric data by tailored applications of the network analysis. As presented in more detail below examination of such network attributes as newcomers, giant component or clustering, instantiates the processualist approach whereby different phases of routine development represent a single, though multidimensional process with a mixture of different mechanisms which underlie it (Kawalec, 2020).

The paper is organized as follows. In the first section construction of datasets and methods of network analysis are presented. The next two sections examine, respectively, Unified Growth Theory as a subroutine of the economic growth theories and the influence of the former on the cognitive dynamics of the latter. In the final section the research findings are summarized and the main research limitations are presented. Figures with time series are collated in the annex.

\section{Data and methods}

The construction of each particular concept of research routine requires a combination of content analysis of the pertinent narratives (e.g. original articles, review papers, interviews, archival material) with a network analysis of the pertinent bibliometric data (sometimes also of other kinds of data, such as patenting). The analyses presented in this paper are based on datasets constructed from Scopus and the Web of Knowledge databases. Three main datasets were constructed: the GROWTH dataset-related to the overall field of economic research on growth; the UGT dataset-related to the sub-routine of Unified

\footnotetext{
${ }^{3}$ Imre Lakatos initiated a different meso-level analysis of science dynamics in terms of research programmes, which influenced the methodology of economics. However while he ignored the social-institutional aspect of the dynamics it is difficult to reconstruct his concept from bibliometric data.
} 
Growth Theory and the BASE dataset-related to the early impact of Unified Growth Theory.

The GROWTH dataset was constructed from Scopus by searching "growth" and "theory or model" in the title-abstract-keyword field combined with limiting subject area to economics and excluding the current year 2020. A number of alternative approaches was explored that varied from 56 to 800,000 publications. As a testbed a set of 12 publications of Paul Romer was used to assess the adequacy of a particular search setup. The one presented in the paper turned out to be the most adequate one capturing the relevant eight of 12 papers.

GROWTH contains basic bibliographic information, affiliation and cited references for the total of 32,919 publication records (covering 40,684 authors, 154,449 cited authors, 802,283 cited references and 52,039 keywords). While the publications in GROWTH range from 1953 to 2019 Scopus started to record cited references as late as 1970. Separate subsets of the dataset GROWTH were constructed for a network evolution analysis (as the algorithm used for computations has a limit of 30,000 units) extending to 2014 or 2015 depending on the kind of data analysed and also separate subsets were generated for the calculation of annual frequencies of author, cited references and keyword data.

The UGT dataset was constructed from Scopus on the basis of a search for papers containing citations of the titles of the funding publications of Oded Galor (Galor \& Weil, 1999, 2000; Galor, 2011) as initially indicated by (Perrin, 2011). UGT contains basic bibliographic information, affiliation and cited references for a total of 1,286 publication records (covering 1,584 authors, 48,358 cited authors, 74,364 cited references and 3,029 keywords). Subsets of the dataset UGT were constructed for the network evolution analysis and also separate subsets were generated for the calculation of the annual frequencies of author, cited references and keyword data.

The BASE dataset was constructed from the Web of Knowledge by the same search criteria as the GROWTH dataset described above and by limiting the timespan to 1989-2005 mainly because (Romer, 1986) is not recorded in Scopus. The analyses of the citation dynamics of each of the most cited publications in GROWTH (Lucas, 1988; Romer, 1986, 1990) and UGT (Galor \& Weil, 2000) determined that the period of 1989-2005 was critical for the adoption of the concepts specific to the symbolic representation of the Unified Growth Theory as an endogenous growth model. BASE contains basic bibliographic information, affiliation and cited references for the total of 8,472 publication records (covering 9,851 authors, 66,002 cited authors, 151,236 cited references and 8,240 keywords). Twenty specific keywords were manually extracted from the above mentioned publications with the aid of additional literature, most notably (Barro \& Sala-i-Martin, 2003; Perrin, 2011). To mitigate the problem of incomplete record description (such as missing keywords and abstracts in Romer 1986, 1990 or contingency of author-provided keywords) all the records (by title, abstract and keywords) in BASE were annotated with 
the twenty keywords. It has to be stressed that the databases used in this study allow only an indirect and imprecise capture of the changes in symbolic representation of growth theories by means of newcomer authors or keywords in contrast to such databases as MEDLINE which maintain their own consistent classificatory schemes and metadata for publications. A clustering analysis of the annotated BASE dataset revealed that the twenty keywords group in three topical areas (represented respectively by "endogenous growth", "human capital" and "demographic transition" as the central nodes), so for each of them a separate dataset was extracted from BASE for a more pertinent analysis of citation patterns.

The results presented here are based on simple frequency counts and the standard attributes of networks such as "newcomer", "giant component" and "clustering". The concept of newcomer has a long-standing tradition in the analysis of the dynamics of networks in particular involving authorship. It is assumed that one of the fundamental mechanisms leading to expansion of a collaboration (co-author) network is by attracting talents who have not yet participated in the network and thereby leading to the generation of new ideas. Each co-occurrence (such as co-authorship or co-occurrence of cited references or keywords) in a single source is marked by a link in the network and the subset of the network which has the highest number of linked nodes (e.g. author) is dubbed "giant component", so for instance in the fully connected network the giant component is identical to the whole network. In general terms if the giant component contains $50 \%$ of all nodes of the network it dominates the network. In the case of research routine this point marks the mature phase in its evolution (Kawalec, 2018b). Clustering is based on proximity relationships in the network measured by co-occurrence in source publications, and represents a bottom-up classification of the nodes in the network such as thematically linked co-authorship relationships. VOS viewer software was used for the clustering analysis and presentation and Gephi software was used for the presentation.

To enhance understanding of the evolution of Unified Growth Theory and growth theories in general the paper uses the concept of research routine which was recently introduced in the philosophy of science. The latter is defined as "a repeated and recognizable pattern of research practices of a scientific community which share a symbolic representation" (Kawalec, 2018b) and constitutes the main source of the heuristics-driven variance for each time a given research routine is used in a particular research process as it is enacted in a modified way due to specific research question and research design. It needs to be stressed that the concept of research routine captures dual dynamics: 1) cognitive (related to the elaboration of its symbolic representation) and 2) institutional (related to the diffusion and social impact of the routine). This paper mostly focuses on the cognitive dynamics of economic growth theories as a research routine. 


\section{Unified Growth Theory as a research sub-routine of economic growth theories}

Even without a comprehensive analysis of the evolution of economic growth theories which is outside of the scope of this paper it is quite apparent that it follows a typical path of phase dynamics that characterizes research routines in general. It is the kind of dynamics that was projected by de Solla Price (1951) in his early contributions to scientometric research on academic performance. What he predicted was that scientific research would typically proceed by short periods of rapid advancement which are then followed by longer periods of a much slower pace of progress. One explanation he entertained was that the latter longer periods are needed as assimilation of the breakthrough discoveries and as incubation of the subsequent ones.

This kind of transition phases is often attributed to the development of the research on economic growth. The sudden increase in research interest in this topic, at least in the early phases, also reflects the changes in the economy itself-both in time and across different countries as for instance the transition from Malthusian era to the post-WWII Maddison's "golden age", or the widening post-1960's gap between the East Asian economies and post-colonial Sub-Saharan African economies (Howitt \& Weil, 2010). ${ }^{4}$ The emergence of the major shifts in economic growth theories can typically be pinned down to particular publications, recently being most often articles (see Figure A3). Moreover those breakthrough contributions accommodate a substantial body of theoretical accomplishments embodied in the previous ones (Barro \& Sala-i-Martin, 2003, pp. 16-20). The initial phase of the emergence of economic growth theory as a distinct research field in economics is identified with the contributions of Adam Smith, Thomas Malthus, David Ricardo, or John Stuart Mill. Gavin Cameron (2010, p. 9) succinctly characterizes those contributions as stemming from the broader cultural milieu of Enlightenment:

Being products of the Enlightenment, the classical economists shared a concern for human progress that would do credit to a modern policymaker. One purpose of their analysis was to identify the forces in society that promoted or hindered progress and to provide a basis for policy and action in a time of considerable political innovation ... and revolution.

The theoretical context for these early contributions were theories of value and theories of distribution. One of their pervading problems was a lack of clear distinction between short- and long-time macroeconomic phenomena. Nevertheless as Cameron claims they cannot be dismissed out of hand as "growth theorists' manqué", because they were concerned, even if using different

\footnotetext{
${ }^{4}$ This may be one explanation why the economists in the aftermath of the Great Depression were rather sympathetic to the instability of growth entailed by the Harrod-Domar model.
} 
vocabulary, with the same pertinent issues: "technical change, specialization, factor substitution, and factor accumulation, ... the effects on these of trade, institutions, inequality, political economy, geography and population size and growth" (2010, pp. 10-11). To stress the point Cameron refers to citation patterns of these classical works in volume 1 (A and B) of the Handbook of economic growth (Aghion \& Durlauf, 2005). This observation is also confirmed by the respective citation patterns in GROWTH which exhibits sustained interest in the classical contributions to growth theory (Figure A1).

The classical growth theorists shared the common conclusion that eventually the process of economic growth will asymptotically lead to a state of stagnation (the "stationary state"). As it turns out this conclusion, however, was based on an incorrect analytical framework. It was wrongly assumed that population growth will keep wages at subsistence level, capital would only be accumulated out of profits, and land was assumed as the central factor of production:

Economic progress has shown that the possibility of investment in human capital can lead to a demographic shift whereby households choose 'quality' over 'quantity' in their reproductive choices; that saving by workers can be an important source of capital accumulation; and that factor substitution tends to prevent the inexorable rise in the price of any factor, even if it is in fixed supply (Cameron, 2010, p. 14).

Then followed a long period of disinterest in the topic which was again revived under the influence of John M. Keynes. In the interim period at around 1870 's economic research was thoroughly changed by the elaboration of the abstract mathematical modelling and most relevant developments as the production and utility functions. All these developments marked a difference between the first theories of economic growth and precursors of modern theories (Boianovsky, 2018; Halsmayer \& Hoover, 2016) such as in the works of Roy Harrod (Harrod, 1939) and Evsey Domar (Domar, 1946).

Again after a much shorter time the first modern neoclassical growth model was formulated by Robert Solow (Solow, 1956, 1957; Hagemann, 2009) and independently by Trevor Swan (Swan, 1956). While the Solow-Swan model had sparkled a new wave of studies on economic growth and some major contributions Solow himself in his subsequent publications was able to partly alleviate the debatable assumption of the exogeneity of technological change. ${ }^{5}$ The Solow-Swan model, however, has the obvious shortcoming that the long-run per capita growth rate is determined by the rate of technological progress which itself was left out of the model: "Thus we end up with a model of growth that explains everything but long-run growth, an obviously unsatisfactory situation" (Barro \& Sala-i-Martin, 2003, p. 18).

\footnotetext{
${ }^{5}$ For an account of the interim contributors and accomplishments in economic growth theory, see e.g. (Barro \& Sala-i-Martin, 2003; Cameron, 2010).
} 
Next as Robert Barro and Xavier Sala-i-Martin note "Probably because of its lack of empirical relevance, growth theory effectively died as an active research field by the early 1970s, on the eve of the rational-expectations revolution and the oil shocks. For about 15 years, macroeconomic research focused on short-term fluctuations" (Barro \& Sala-i-Martin, 2003, p. 19). The mid-1980s observed a boom in research on economic growth with the contributions of Romer (Romer, 1986) and Lucas (Lucas, 1988). As they tried to alleviate the assumption of the neoclassical Solow-Swan growth model that the long-term per capita growth rate is pegged by the rate of exogenous technological change and determines the long-run growth rate within the model they were dubbed "endogenous" (vs "exogeneous") growth models (Spear \& Young, 2017). One significant improvement over the initial model was the incorporation of R\&D expenditures and imperfect competition which began with (Romer, 1990) and numerous subsequent contributions (Aghion \& Howitt, 1992; Grossman \& Helpman, 1991). In these models technological change is an effect of intentional R\&D activity which yields monopoly advantage. However in those models the long-term growth rate depends on governmental policies (taxation, legal and IP regime, infrastructure, protection of financial markets, etc.) which influence the long-term rate of growth.

Thus the core components of the symbolic representation that constitutes the modern growth theories as the main routine embrace: "concepts such as aggregate capital stocks, aggregate production functions, and utility functions for representative consumers (who often have infinite horizons). [They] ... also use modern mathematical methods of dynamic optimization and differential equations" (Barro \& Sala-i-Martin, 2003, p. 16). Of course particular subroutines will also use different components and different approaches (Joffe, 2017).

The above-mentioned transitions in the development of economic growth research are well established in the pertinent literature. This paper especially Section 3, provides some evidence of yet another transition phase in the evolution of growth theories that was initiated by the publication of Oded Galor and David Weil paper Population, technology and growth (Galor \& Weil, 2000). ${ }^{6}$ Before this a start should be made with an overall characterization of UGT and its place in the context of economic growth research.

An overall characterization of a research routine is the observation of the associated diffusion curves which follow the inverted S-curve (Kawalec, 2020). In that respect the research on economic growth has not yet reached the "saturation phase" (de Solla Price) and is still dynamically developing (Figure A2). The fluctuations described above are to some extent also reflected in the size of the giant component which included $7 \%$ of all authors in 1956 , to drop to $1 \%-2 \%$

${ }^{6}$ The results published in 2000 were widely known earlier as the working version was circulated first (Galor \& Weil, 1998) and also preceded by earlier publications such as (Galor \& Weil 1996; Galor \& Zeira 1993). 
throughout the 1970's and again increased in 1986 to 5\%, steadily growing to $8 \%$ in 2000 and since 2005 consistently growing to $24 \%$ in 2014 .

The clustering analysis of cited authors (Figure 1) reveals eight focal points in the body of literature on economic growth accumulated between 1953 and 2019. Some of them clearly represent the well-known subroutines (exogeneous and endogenous approaches).

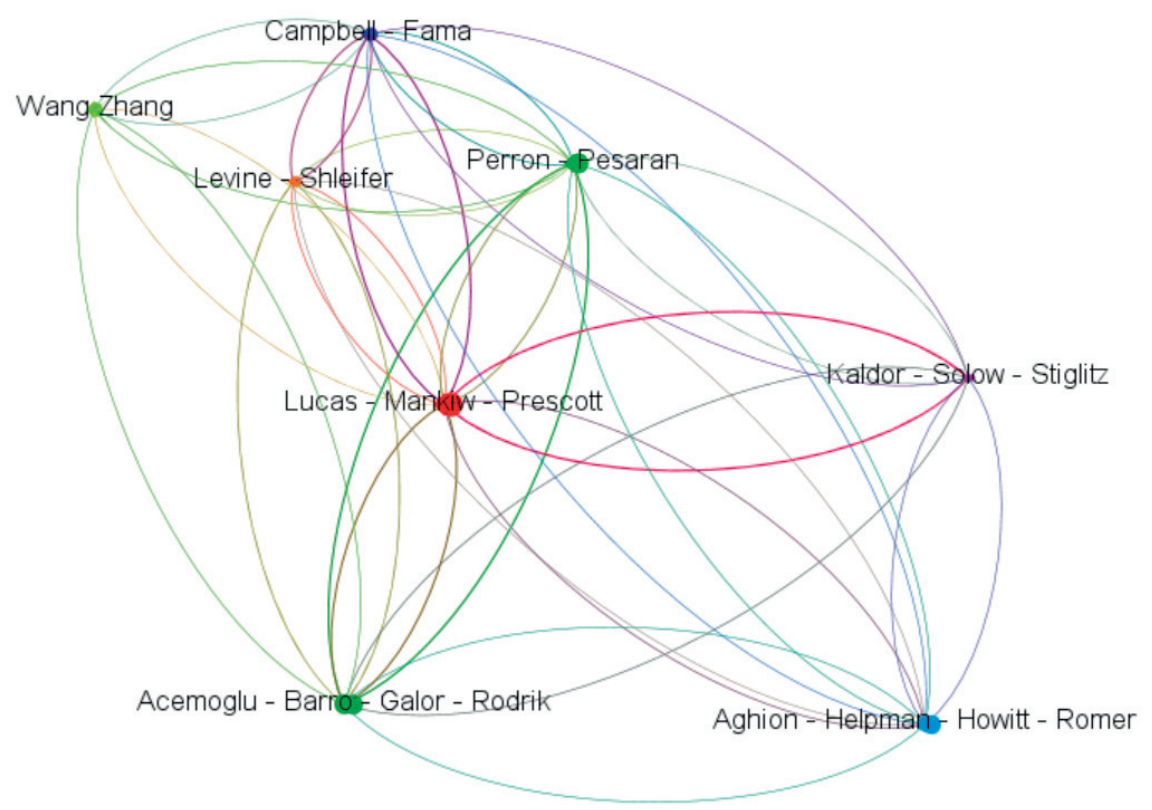

Figure 1. The network structure of the $\mathbf{5 0 0}$ most often cited authors Source: GROWTH dataset (1953-2019).

If judged by the simple frequency of occurrences the conceptual advances in growth theories have been consistently driven by the four most often cited contributions (Figure A3) which were also mentioned above (Lucas, 1988; Romer, 1990, 1986; Solow, 1956).

Unified Growth Theory, in contrast, has apparently been developed predominantly around the contributions of Galor and his collaborators (especially David Weil). While the three most often cited contributions are (co-)authored by Galor (Figure A4) it was the initial paper (Galor \& Weil, 2000) that remains the main reference for contributions on Unified Growth Theory along with to his extensive review paper (2005) and monograph (2011).

Typically the development of research routine is determined by the growing number of authors (including new talents attracted to the field- "newcomers") and a parallel expansion of the largest connected subnetwork-the so called 
"giant component" - which embraces a growing percentage of collaboration links between authors within-what Merton dubbed-the "invisible college". For instance the mature phase in the development of another research routine studied elsewhere (Kawalec, 2018a, 2020) was marked by the point when the giant component exceeded $50 \%$ of all authors publishing annually.

Thus it is remarkable that the giant component within the UGT routinepresented in Figures 2 and 3-embraces only 5\% of all contributing authors. Presumably the social sciences in general are characterized by more significant dispersion and variety of subnetworks of collaborating authors as a result of the simultaneous co-existence of different theoretical frameworks or versions of growth models in economics. But there may be a special reason for this kind of dispersion in the case of Unified Growth Theory. As the latter is a subroutine of the main growth routine the primary collaboration networks for the majority of scholars working on Unified Growth Theory may be identified within the main routine. This supposition is developed further in the next section. The overall clustering structure of Unified Growth Theory is quite dispersed and the giant is not connected (Figure 2).

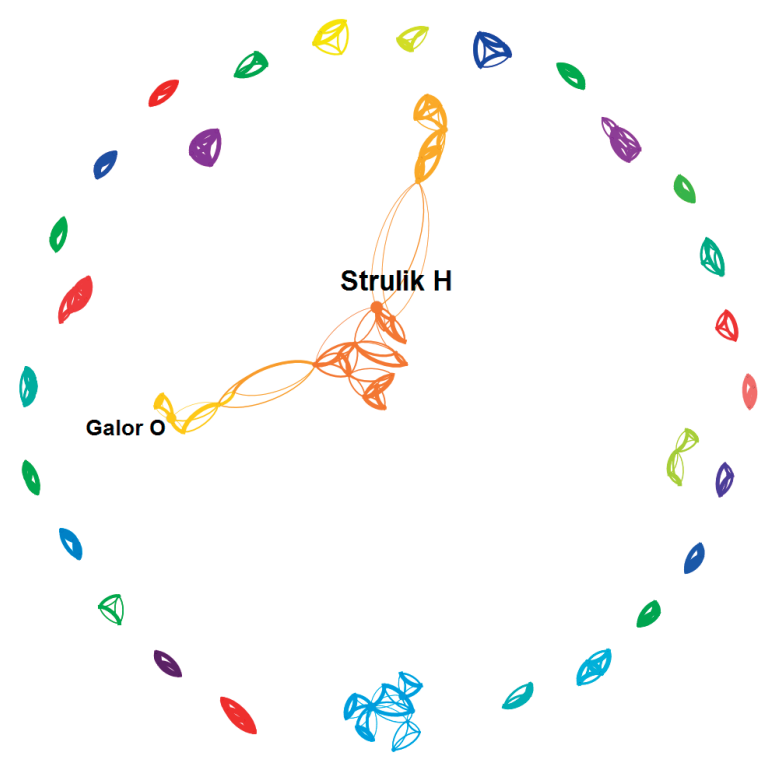

Figure 2. The network structure for 500 top publishing authors in UGT Source: UGT dataset (1999-2019).

The complete structure of the giant component embracing 79 of 1,584 authors in UGT dataset is presented in Figure 3. Note that more recently Holger Strulik has become the central hub for developing co-authorship relationships, although Galor's publications are still the ones most cited (Figure 3). 


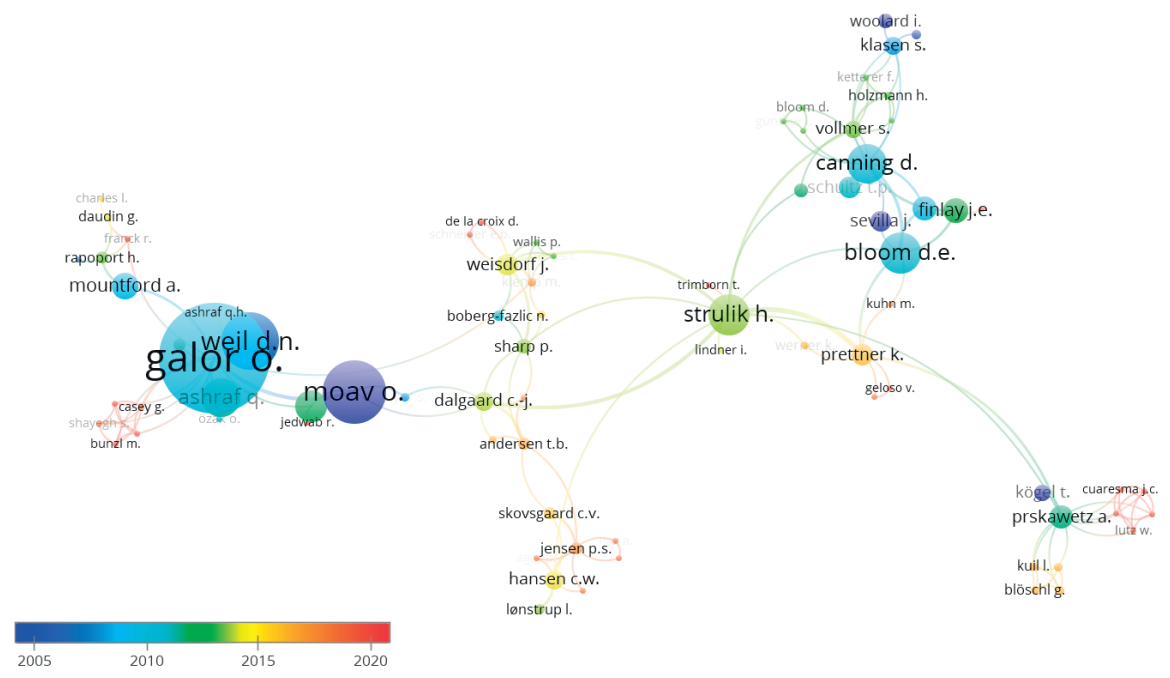

Figure 3. The giant component of co-authorship in the subroutine (includes 79 of 1,584 authors). The node size reflects citations. The colour corresponds to the average publication year for a given author Source: UGT dataset (1999-2019).

While Strulik has recently become the most prolific contributor the main routine represents a much stronger tendency for author collaboration (Figure A8). These two tendencies may jointly have the effect that for the more recent contributions (Figure 3) Strulik has become the central hub.

The dynamics of Unified Growth Theory shares several important features with growth theories. The difference in absolute numbers notwithstanding it has similar dynamics of the authors contributing to the subroutine (Figure A5).

Moreover, the clustering in the main routine and the subroutine have been growing at a similar level. One could expect that the authors contributing to the subroutine participate in the clustering of the main routine (Figure A6).

The methods used in this paper allow for a very limited assessment of the interaction between the cognitive dynamics of the main routine and the subroutine. However the evidence may suggest that the symbolic representation of Unified Growth Theory is driven by the overall dynamics of growth theories. For instance the growth rate of the number of publications or their generativity in terms of bringing new unique keywords (keyword newcomers) are very much alike with 2,5 and UGT 1,7 on average. What it could mean is that there is no clear evidence that ideas generated within Unified Growth Theory subroutine have a noticeable impact on the main routine. Moreover, the major conceptualizations within Unified Growth Theory seem to have been inherited from the main routine, perhaps with the exception of the specific concept of demographic transition. 
As the initial clustering of topics in the subroutine was significantly lower than in the main routine and only with time has it grown in a similar way it strongly suggests that its dynamics were driven by the main routine rather than the other way round. Nevertheless there are, as will be argued in more detail in the next section, some important caveats to this observation which indicate the unique role that Unified Growth Theory has played in shaping the main routine.

Despite some obvious dependencies of the subroutine on the main routine it has developed quite independently from the latter. Consider first the observation that the ten top most cited authors in both groups differ remarkably (Figure 4).

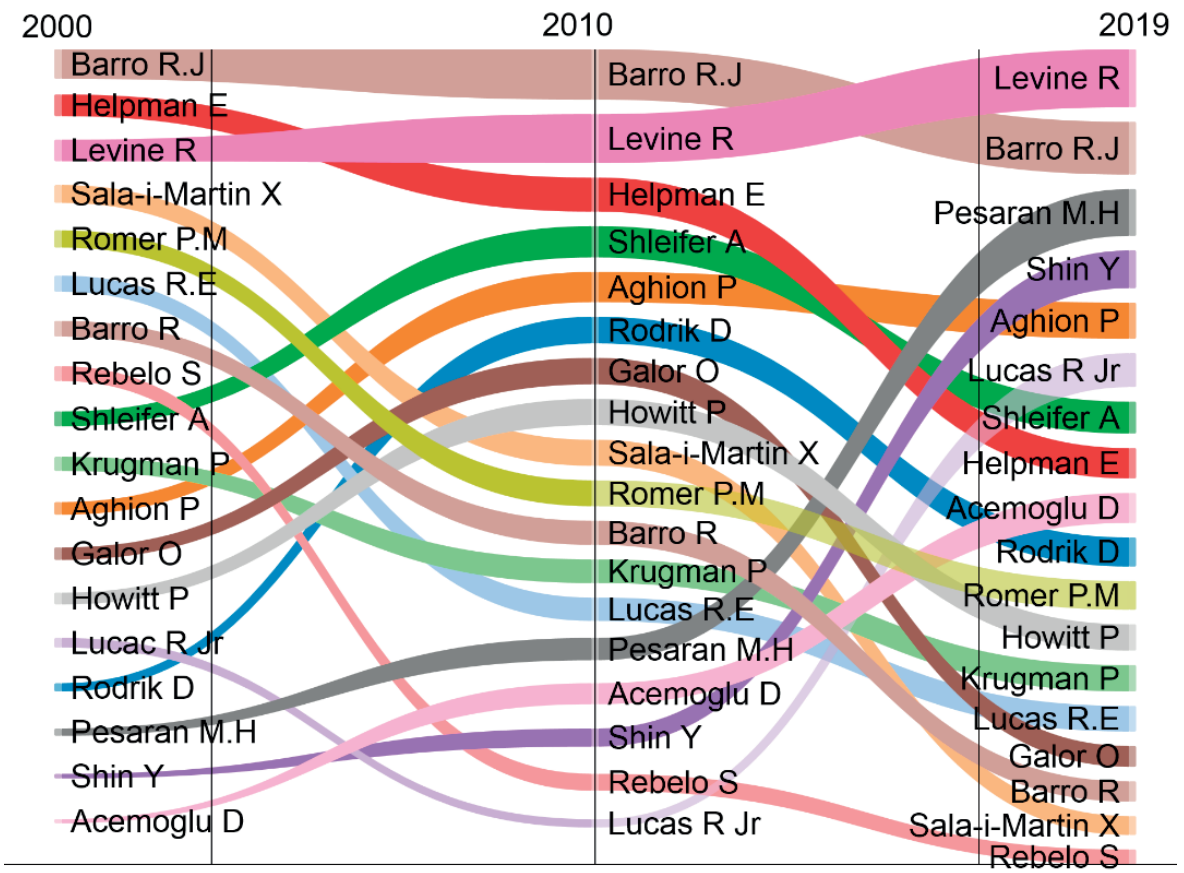

Figure 4. Sankey graph for the ten top cited authors in each of three periods in GROWTH

Source: GROWTH dataset (2000-2019).

As evident by his central role in the network of top ten cited authors (Figure 5) Galor is the main contributor to Unified Growth Theory.

It is remarkable that the main contributors to the main routine such as Lucas, Romer, Solow, Lucas are absent from the top cited UGT authors. In other words they are not in the focal area of the subroutine. The next section examines in more detail the impact of Unified Growth Theory subroutine on 


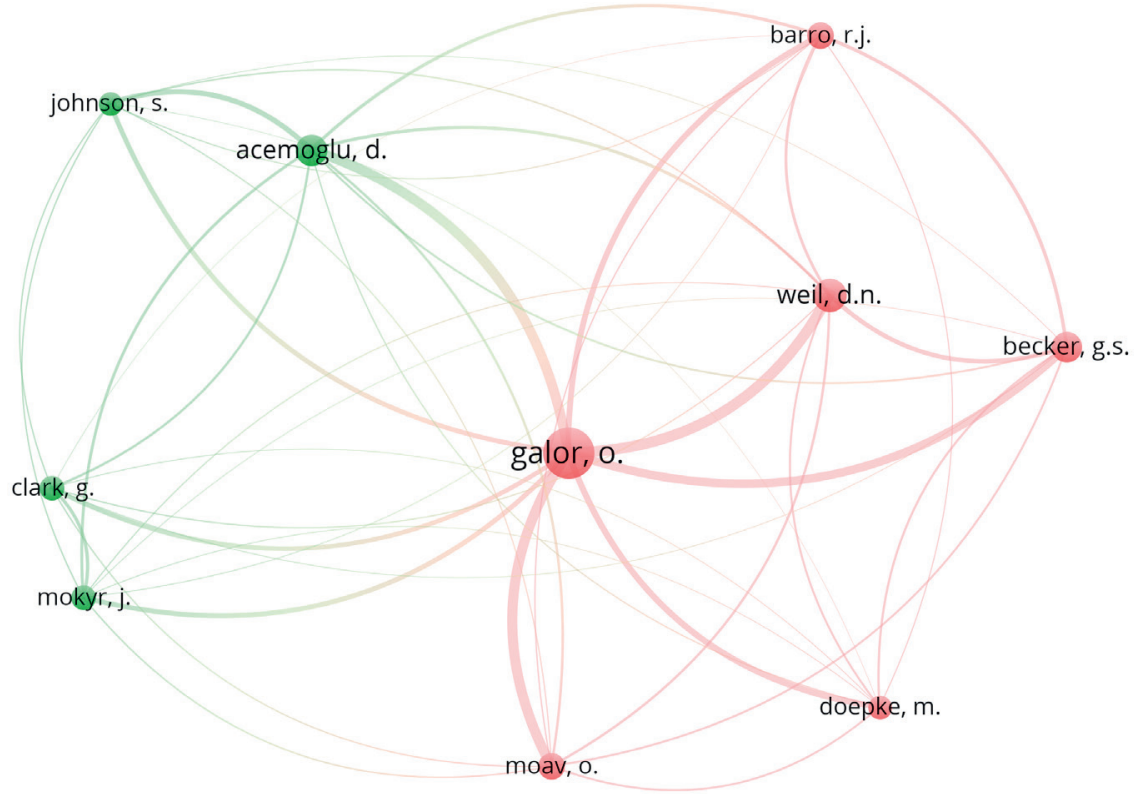

Figure 5. The co-citation network of the ten top cited authors in the subroutine Source: UGT dataset (1999-2019).

the main routine. For that purpose it will focus on the most salient aspect-in bibliometric terms - of the symbolic representation developed within Unified Growth Theory, namely "demographic transition".

\section{Influence of demographic transition on the symbolic representation}

Unified Growth Theory is motivated by the fundamental observation that the modern growth theories only partially capture the phenomena related to growth and that they essentially ignore the underlying development mechanisms with the resulting qualitative changes. It is the latter that not only drive the phase transitions observed over long periods of time but also in global cross-country comparisons: "What is needed is a unified theory that can account for the major features of the prolonged Malthusian era as well as the transition to the modern growth regime" (Snowdon \& Galor, 2008, p. 101).

To elaborate a comprehensive understanding of the economic growth Galor and his collaborators distinguish three main phases throughout economic history that need to be explained and captured within a single dynamic system (Galor, 2005, pp. 174-177): the Malthusian stagnation, the industrial revolu- 
tion and great divergence. ${ }^{7}$ Faustine Perrin (2011, p. 364) illustrates those three phases following (Maddison, 2001) and (Clark, 2007), with the transition phases of real income per capita in England from 1200 to 2010. The initial Malthusian stagnation was characterized by slow growth, absence of breakthroughs in technology and the positive influence of income per capita on population growth (Malthus, 1798; Ashraf \& Galor, 2011, 2008; Snowdon \& Galor, 2008, pp. 109-110). The era of industrial revolution started at the beginning of the 19th century and was characterized by technological change and industrialization as well as a positive correlation between income and population growth: "a significant increase in the growth rate of output per capita generat[ed] an unprecedented increase in population growth" (Perrin, 2011, p. 365). The third phase of great divergence started in the last quarter of the 19th century and was marked by an acceleration of technical change and its interaction with the accumulation of the human capital, a negative correlation between income per capita and population growth as well as the resulting divergence across countries. One of specific phenomena related to the progression from the second to the third growth phase is "demographic transition": "This process accounts for the transition from high birth and death rates to low birth and death rates" (Perrin, 2011, pp. 365-366). For countries that entered the last phase the rate of population growth dropped from $0.77 \%$ per year (in $1870-1913$ ) to $0.42 \%$ (1913-1950). The demographic transition enabled "economies to convert a larger share of the fruits of factor accumulation and technological progress into growth of income per capita" (Galor, 2005, p. 198). The influence of demographic transition on the growth process was threefold: (i) the reduction of the dilution of the growing stock of capital and infrastructure by increasing resources available per capita; (ii) increase of investment in human capital and labour productivity by the re-allocation of resources from the quantity of children towards their quality and (iii) the change of the age distribution of the population with a temporal increase of the fraction of the labour force in the population and the resulting increase in productivity per capita (Galor, 2011, pp. 46-54; Ashraf \& Galor, 2018). Galor argues that demographic transition with the decreased fertility rates was not an outcome of the rise in income or wages of women during industrialization nor the reduction of mortality rates. In contrast to the previous conceptions (Becker, 1960; Becker \& Barro, 1989; Gori 2019) Unified Growth Theory treated demographic transition and fertility rates as an outcome of the rise in the demand for human capital in the second phase of industrialization which triggered the onset of institutional changes in formal education (Galor, 2011, pp. 115).

Moreover, it demonstrated that the relationship between human capital and per capita GDP growth across countries exhibits non-linearities and "may result in multiple equilibria including low-growth or poverty traps” (Pelloni, Stengos,

\footnotetext{
${ }^{7}$ For a different conceptualization see (Gomułka, 2009).
} 
\& Valenti, 2019, pp. 3). The concept of demographic transition explains also why the cross-country divergence in living standards occurred not at the outset but a later phase of the industrial revolution (O'Rourke, Rahman, \& Taylor, 2019) and it leads to empirical implications exhibiting a different dynamics of convergence than the Solow-Swan model (Cervellati, Meyerheim, \& Sunde, 2019). Recently a causal link between demographic transition, fertility rate and structural transformation which enabled a shift from agriculture to manufacturing has been demonstrated (Ager, Herz, \& Brueckner, 2020). However the role of $\mathrm{R} \& \mathrm{D}$ activities which is one of the concerns in endogenous growth models is less explored here (Okada, 2020).

The present study shows that the concept of demographic transition with its reconsidered understanding of human capital, population growth and learning (formal education) had a strong impact on the essential part of the symbolic representation of the main routine. A preliminary analysis of the citation patterns of (Lucas, 1988; Romer, 1986, 1990; Galor \& Weil, 1996, 2000) established that this effect is most apparent in the period 1989-2005 which was critical for the adoption of the endogenous growth and the unified growth models. As one would expect demographic transition in the period 2000-2019 is identified as the most often mentioned concept within publications contributing to the subroutine. In order to compare the role of demographic transition in the subroutine and the main routine other nineteen related terms were identified among the 5\% most frequently used keywords in the UGT dataset (embracing almost $50 \%$ of all keyword occurrences). ${ }^{8}$ Unexpectedly the analysis of the period 1999-2019 demonstrated that the frequency of the 20 keywords related to the concept of demographic transition (Figure A7) in the main routine as captured in the GROWTH dataset (32.919 publications and 52,039 keywords) is almost the same as their frequency in the much smaller UGT dataset (1,286 publications and 3,029 keywords). The most plausible explanation is that Unified Growth Theory subroutine has permanently transformed this part of the symbolic representation of the main routine.

To better grasp the impact of Unified Growth Theory on the main routine in growth theories with regard to concepts related to demographic transition a more focused study was performed. By analyzing the citations of the most influential publications (Lucas, 1988; Romer, 1986, 1990) and (Galor \& Weil, $1996,2000)$ it was determined that the critical period to establish their impact on the relevant literature was 1989-2005. Further in order to avoid the problem with missing abstracts and keywords, which is particularly common

\footnotetext{
${ }^{8}$ The complete list includes the following keywords (ordered by UGT frequency): fertility, population growth, demographic transition, population dynamics, mortality, life expectancy, demography, birth rate, population, evolution, population size, fertility transition, fertility decline, demographic trend, overlapping generations, population decline, infant mortality, demographic history, natural selection, reproduction.
} 
for the records until the 1990's, 20 specific keywords were manually extracted from the above mentioned five papers and used to annotate titles, abstracts and keywords of 8,470 publications on theories or models of economic growth that appeared between 1989-2005. The clustering analysis performed on the annotated BASE dataset demonstrated that they form three distinct but connected clusters centred around the concepts of: 1) endogenous growth, 2) demographic transition and 3) human capital (Figure 6).

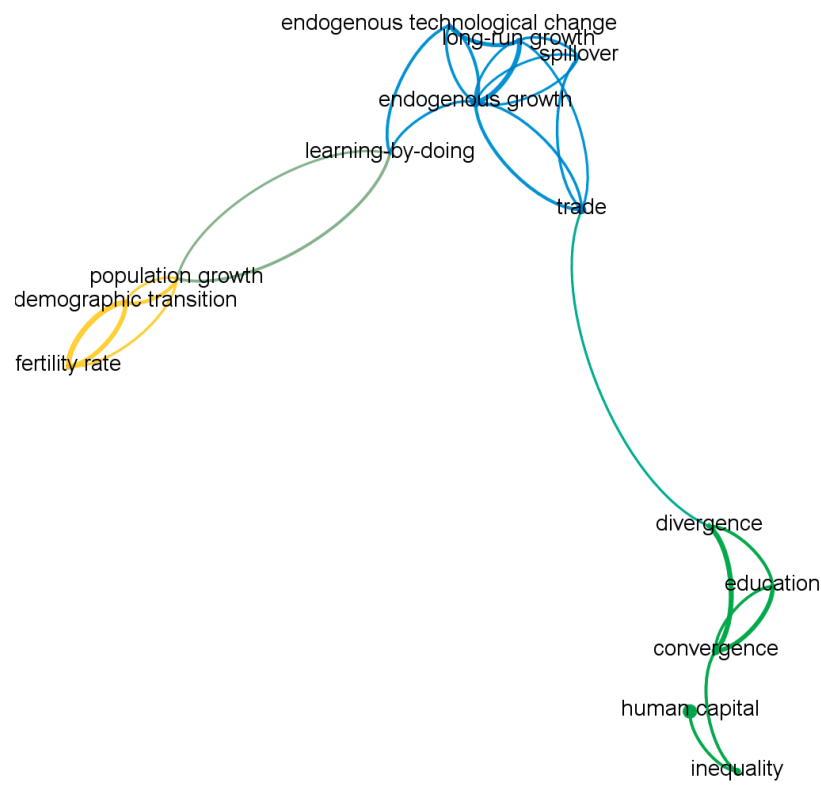

Figure 6. Clustering of 20 specific keywords extrated from (Lucas, 1988;

Romer, 1986, 1990; Galor \& Weil, 1996, 2000)

Source: BASE dataset (1989-2005).

This grouping reflects closely Galor's conceptual shift in defining demographic transition and the related concepts of fertility rates and population growth as an outcome of economic incentives. It is evident as all the links-and thereby also influence-between demographic transition and human capital, education and income per capita presented on Figure 6 are intermediated by economic activities. Moreover, the strong ties that demographic transition has with the essential concepts of the symbolic representation of the main routine of economic growth indicate that Unified Growth Theory had, in this regard, a strong impact on the development of the main routine.

This supposition is further explored by analyses of the contribution of Galor's publications in each separate area of the three clusters presented in Figure 6. To perform each of the analyses presented below the relevant subsets of the an- 
notated BASE dataset were extracted for the specified keyword (human capital, education, demographic transition, fertility rate, exogenous growth). Note that at this stage the symbolic representation within the emerging endogenous growth theory developed a markedly different understanding of learning and knowledge acquisition as emerging in production during the processes dubbed by Kenneth Arrow "learning by doing". In contrast Galor's theory propounded a different mechanism of knowledge acquisition resulting from institutional changes in formal education (Figure $7 \mathrm{~b}$ ) that directly informed the formation of the stock of human capital (Figure 7a). If judged by similarity measures in the clustering presented in Figure 6, it was the latter learning mechanism that turned out to be more relevant to the understanding of the human capital within the main routine.

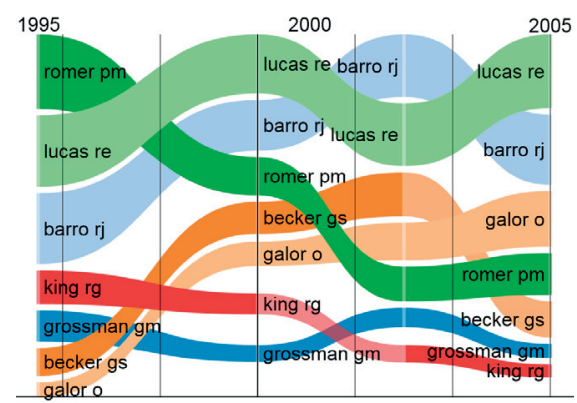

(a) human capital

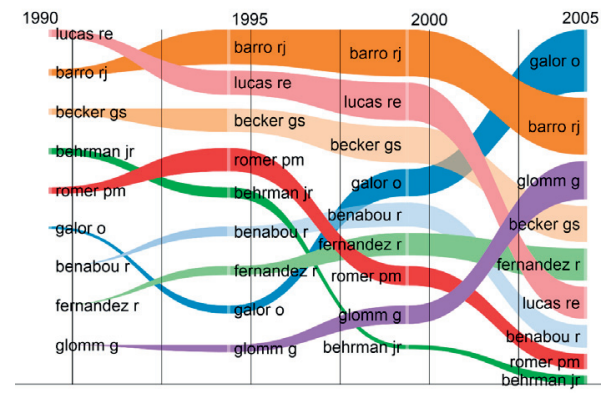

(b) education

Figure 7. Sankey graphs for the five top cited authors in each of three periods Source: Subsets of the annotated BASE dataset (1989-2005) subtracted for the keyword: (a) human capital; (b) education.

Unified Growth Theory builds on Gary Becker's (1960) analyses of endogenised fertility to establish a causal link between the rise in the demand for human capital in the second phase of industrialization and demographic

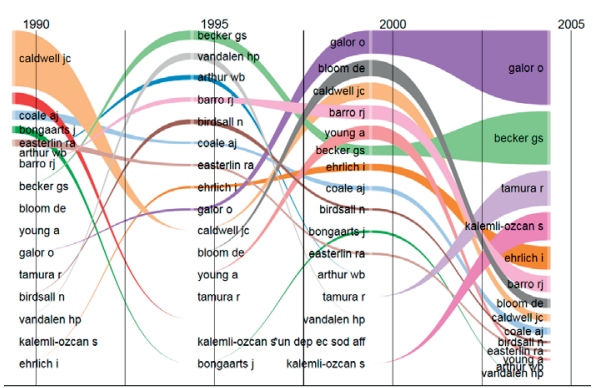

(a) demographic transition

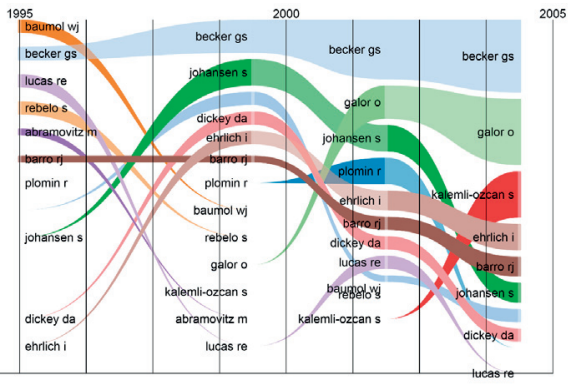

(b) fertility rate

Figure 8. Sankey graphs for the five top cited authors in each of three periods Source: Subsets of the annotated BASE dataset (1989-2005) subtracted for the keyword: (a) demographic transition; (b) fertility rate. 
transition. The changes in citation patterns presented in Figure 15 demonstrate that this indeed has been accomplished in the main routine.

While Galor's direct contributions to the focal cluster of endogenous growth (Figure 6) are less frequently mentioned and are dominated by Romer, Lucas, Aghion, Benhabib, Barro, Grossman and King it has to be stressed that in the overall conceptual structure (as represented by the 20 specific keywords) those three clusters are closely linked and are centrally located in the overall network of all keywords in the GROWTH dataset. Therefore the concept of demographic transition has strongly influenced the essential part of the symbolic representation in the main routine by modifying the concepts of human capital, population growth and learning that are essential to the symbolic representation that emerged in the main routine in 1989-2005.

An interesting question concerns the potential of the subroutine to influence the main routine in the future. As observed in Section 2, the growth theories (with regard to the number of authors) have not yet reached the saturation phase of the diffusion curve which means that they may still develop very dynamically. At the initial stage of development while the number of authors is small a network is usually strongly connected but then-with the growing number of authors-connectivity drops. Apparently (see Figure A8), since 2004 the subroutine's giant component of connected authors, in contrast to the main routine, is not growing and therefore does not yet demonstrate a potential to replace the main routine or shift to a more central place among other subroutines (Figure 1).

The subroutine of Unified Growth Theory in recent years-especially since 2014-seems to have lost some of its initial dynamics as evidenced by the fact that since then the number of keywords does not prominently change while for the main routine it grows on average $8 \%$ annually.

\section{Conclusions}

The paper presents and assesses the complex interaction between the main routine of growth theories and its subroutine of Unified Growth Theory. First, there are a number of common characteristics that both have in common. Second, the evolution of subroutine in some respects is driven by the dynamics of the main routine. The most perspicuous example being the clustering of co-authorship relations. When isolated for the UGT dataset alone the giant component is strongly isolated but the clustering seems to follow the same pattern as the main routine. Third, the subroutine has apparently developed largely independently from the main routine. Even within the large-scale clustering of the main routine Unified Growth Theory marks its relative independence. The latter becomes even more apparent when it comes to the main cited authors and references who significantly differ from the main routine. Fourth, the subroutine 
has impacted the cognitive dynamics of the main routine. This is best evidenced by how the concept of demographic transition altered the essential concepts of the main routine, such as human capital, population growth and learning. Finally, it has to be noted that both the databases and methods chosen have strong limitations in making precise comparative statements on the cognitive dynamics of the main routine and the subroutine. The interdependencies between them may be much more complex than indicated in this paper and to understand them comprehensively a detailed examination of all the other subroutines and their interplay would be needed, starting perhaps with analysis of the eight main clusters represented in Figure 1. 


\section{Annex}

$\rightarrow-$ Smith A_1776_An Inquiry into the Nature and Causes of the Wealth of Nations

--Ricardo D_1817_On the Principles of Political Economy and Taxation

-Malthus T.R_1798_An Essay on the Principle of Population

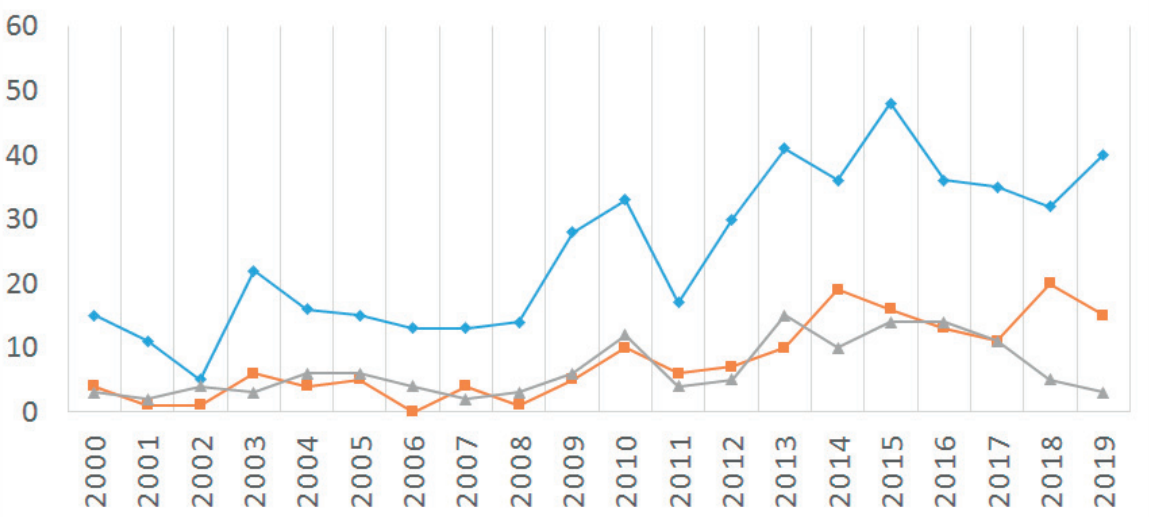

Figure A1. Citations of selected classical authors (following Cameron, 2010) Source: GROWTH dataset (2000-2019).

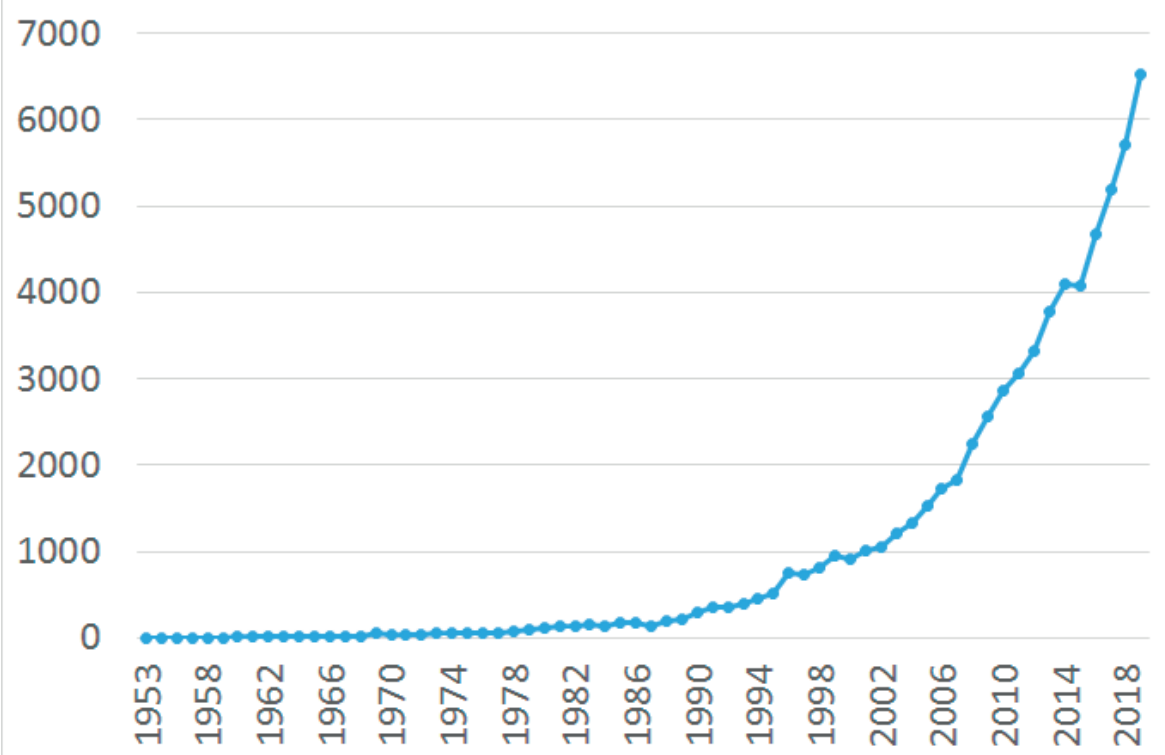

Figure A2. The number of authors in the main routine Source: GROWTH dataset (1953-2019). 


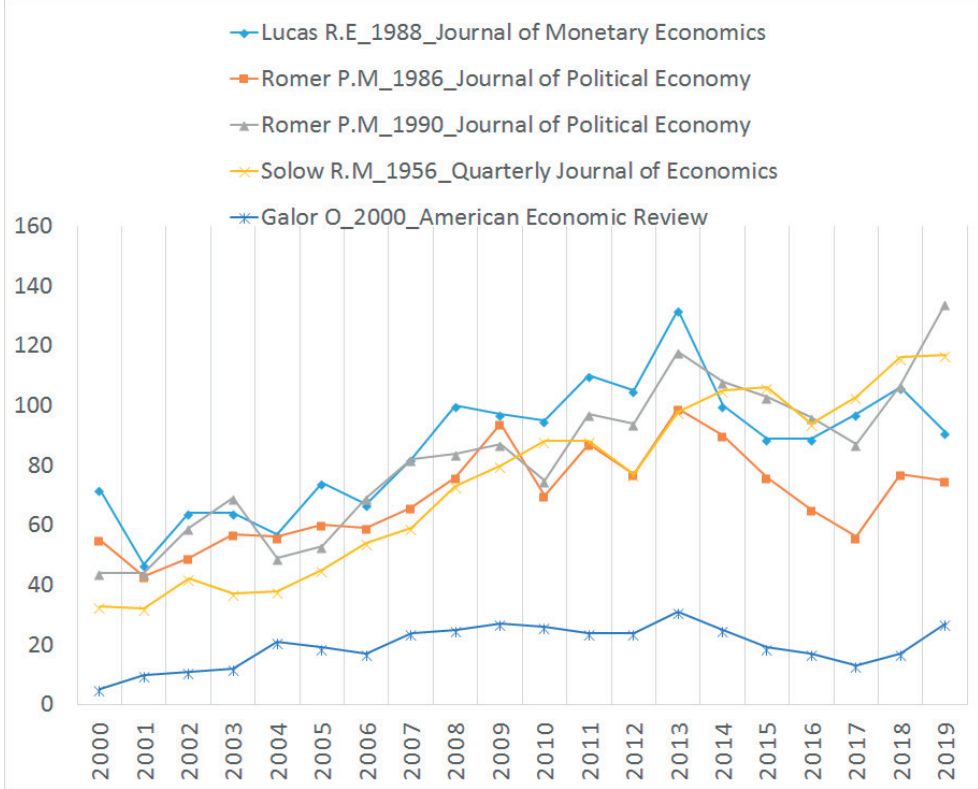

Figure A3. Frequencies of top the four most cited references in the main routine, two references (Galor, Strulik) representing the subroutine and the average citation for GROWTH (close to 0). The presented frequencies are calculated for all duplicates of a source Source: GROWTH dataset (2000-2019).

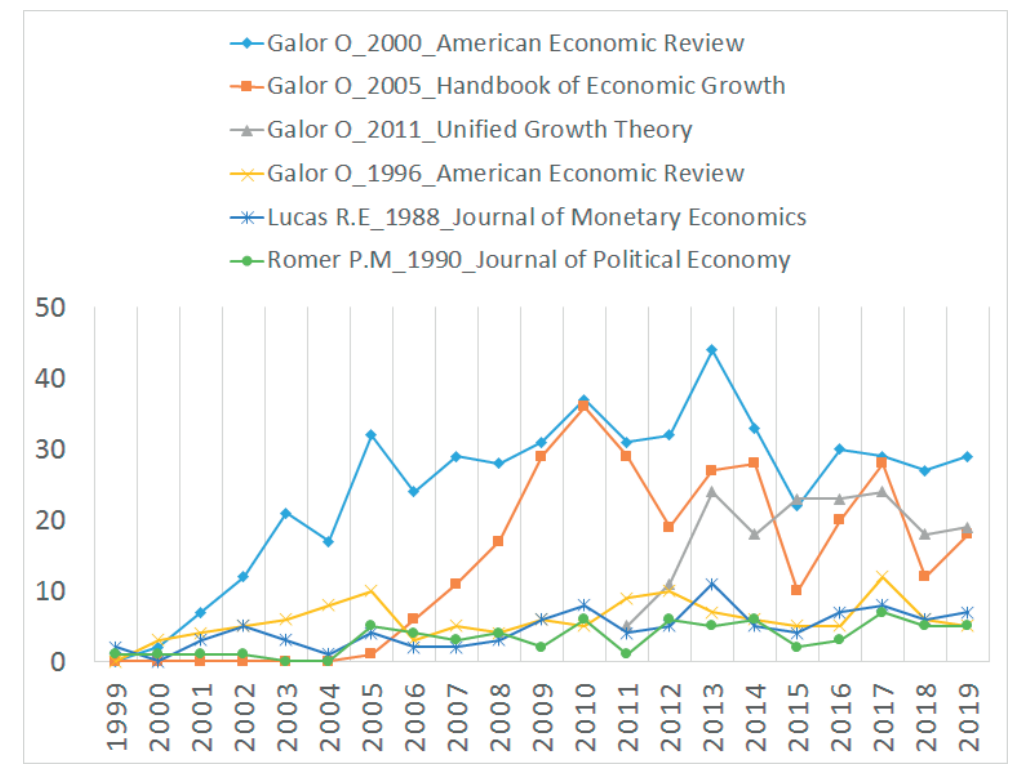

Figure A4. Frequencies of the five top cited references in UGT Source: UGT dataset (1999-2019). 


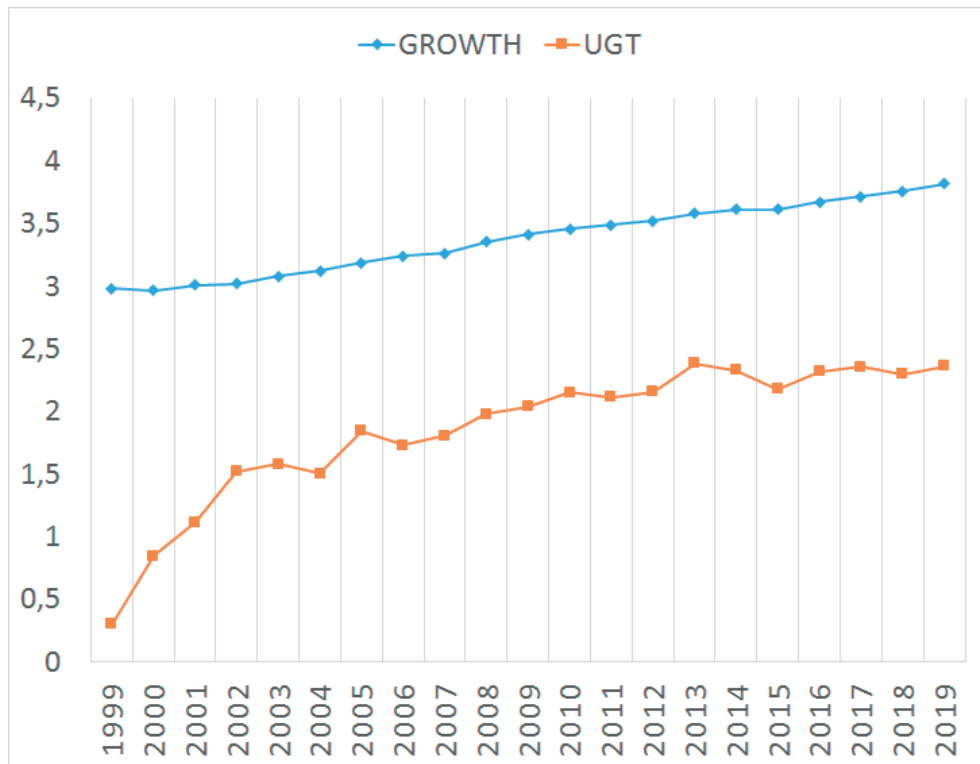

Figure A5. The annual number of authors (logarithmic scale) in the main routine and subroutine

Source: GROWTH dataset (1999-2019), UGT dataset (1999-2019).

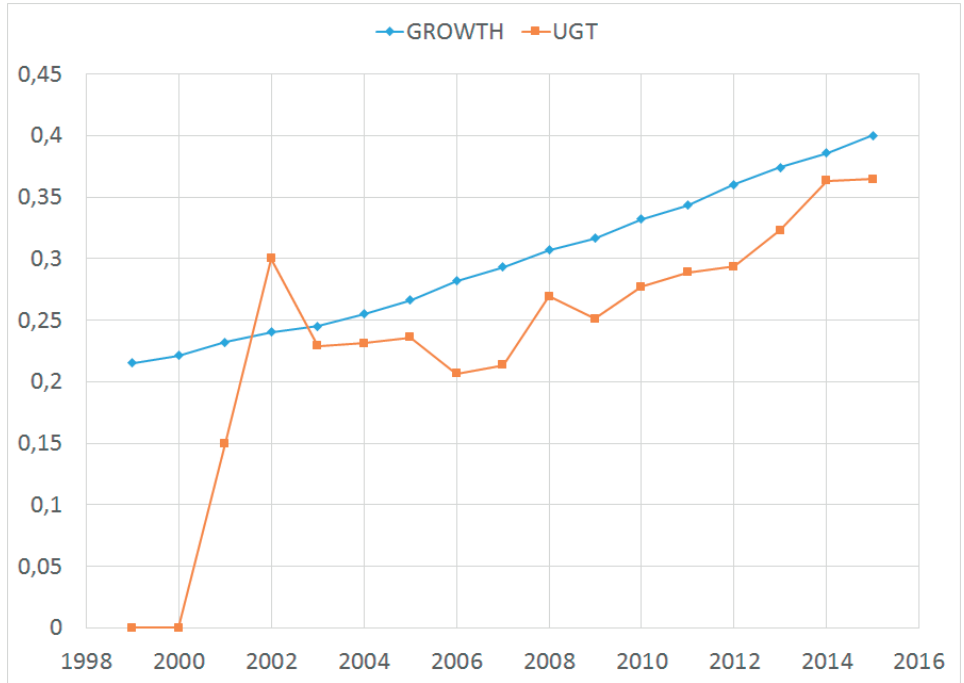

Figure A6. The annual author clustering in the main routine and subroutine

Source: GROWTH dataset (1999-2015), UGT dataset (1999-2015). 


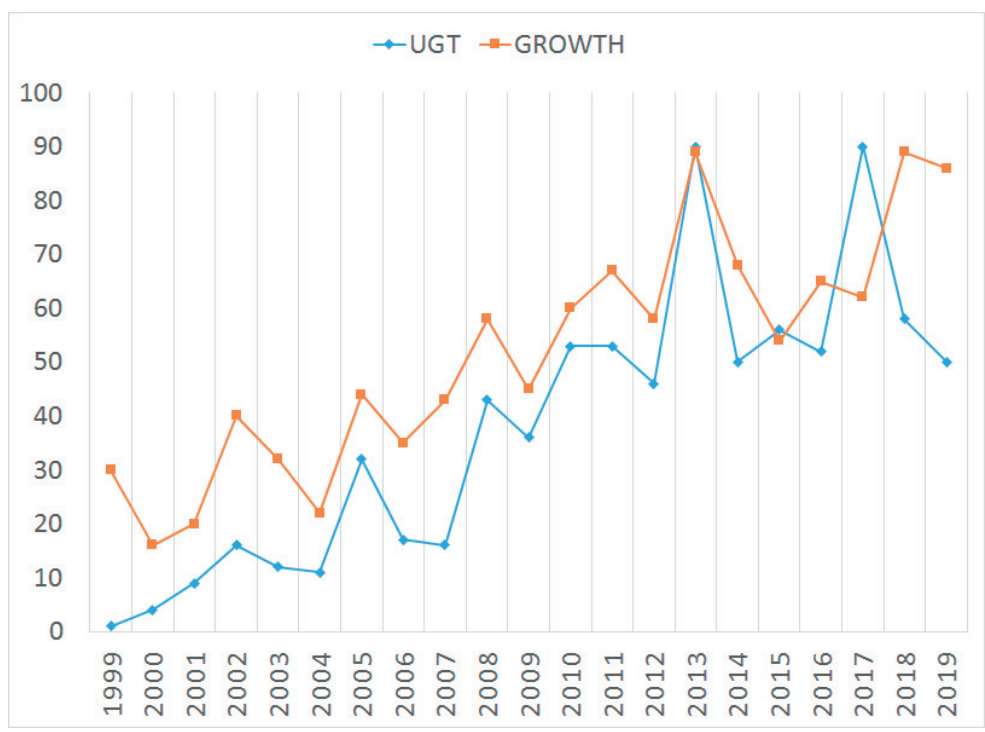

Figure A7. Annual frequencies of demographic transition (average of the 20 related keywords)

Source: GROWTH dataset (1999-2019), UGT dataset (1999-2019).

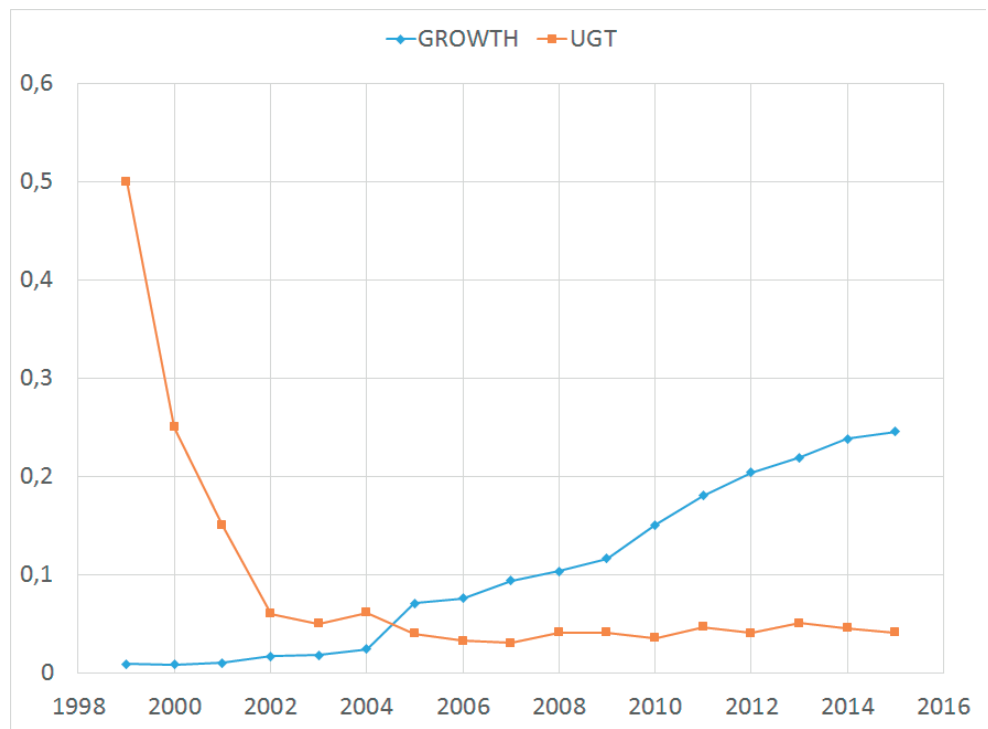

Figure A8. The annual size of the giant component for coauthorship network in the main routine and the subroutine Source: GROWTH dataset (1999-2015), UGT dataset (1999-2015). 


\section{References}

Ager, P., Herz, B., \& Brueckner, M. (2019). Structural change and the fertility transition. The Review of Economics and Statistics, 1-45. Retrieved from https://doi. org/10.1162/rest_a_00851

Aghion, P., \& Durlauf, S. N. (Eds.). (2005). Handbook of economic growth (Vols. 1A1B). Amsterdam: Elsevier.

Aghion, P., \& Howitt, P. (1992). A model of growth through creative destruction. Econometrica, 60(2), 323-351.

Andersen, J. P., \& Hammarfelt, B. (2011). Price revisited: On the growth of dissertations in eight research fields. Scientometrics, 88(2), 371-383.

Ashraf, Q., \& Galor, O. (2008). Malthusian population dynamics: Theory and evidence (Working Paper No. 6).

Ashraf, Q., \& Galor, O. (2011). Dynamics and stagnation in the Malthusian epoch. The American Economic Review, 101(5), 2003-2041.

Ashraf, Q., \& Galor, O. (2018). The macrogenoeconomics of comparative development. Journal of Economic Literature, 56(3), 1119-1155.

Barro, R. J., \& Sala-i-Martin, X. (2003). Economic growth (2nd ed.). Cambridge, MA: MIT Press.

Becker, G. S. (1960). An economic analysis of fertility. In G. B. Roberts (Ed.), Demographic and economic change in developed countries (pp. 209-240). New York: National Bureau of Economic Research, Columbia University Press.

Becker, G. S., \& Barro, R. J. (1988). A reformulation of the economic theory of fertility. The Quarterly Journal of Economics, 103(1), 1-25.

Boianovsky, M. (2018). Beyond capital fundamentalism: Harrod, Domar and the history of development economics. Cambridge Journal of Economics, 42(2), 477-504.

Cameron, G. (2010). Classical economics and economic growth. In S. N. Durlauf \& L. E. Blume (Eds.), Economic growth (pp. 9-15). London: Palgrave Macmillan.

Cervellati, M., Meyerheim, G., \& Sunde, U. (2019). The timing of the demographic transition and economic growth. Economics Letters, 181, 43-46.

Clark, G. (2007). A farewell to alms: A brief economic history of the world. Princeton: Princeton University Press.

de Solla Price, D. J. (1951). Quantitative measures of the development of science. Archives Internationale d'Histoire Des Sciences, 14, 85-93.

de Solla Price, D. J. (1965). Networks of scientific papers. Science, 149(3683), 510-515.

Devlin, W. J., \& Bokulich, A. (Eds.). (2015). Kuhn's structure of scientific revolutions-50 Years On. Cham: Springer International Publishing.

Domar, E. D. (1946). Capital expansion, rate of growth, and employment. Econometrica, $14(2), 137-147$.

Galor, O. (2005). From stagnation to growth: Unified Growth Theory. Handbook of Economic Growth, 1, 171-293.

Galor, O. (2011). Unified Growth Theory. Princeton: Princeton University Press.

Galor, O., \& Weil, D. N. (1996). The gender gap, fertility, and growth. The American Economic Review, 86(3), 374-387.

Galor, O., \& Weil, D. N. (1998). Population, technology, and growth: From the Malthusian regime to the demographic transition and beyond. (NBER Working Paper No. 6811, 
1-52). Cambridge, MA: National Bureau of Economic Research. Retrieved March 10, 2020 from http://www.nber.org/papers/w6811

Galor, O., \& Weil, D. N. (1999). From Malthusian stagnation to modern growth. American Economic Review, 89(2), 150-154.

Galor, O., \& Weil, D. N. (2000). Population, technology, and growth: From Malthusian stagnation to the demographic transition and beyond. American Economic Review, 90(4), 806-828.

Galor, O., \& Zeira, J. (1993). Income distribution and macroeconomics. The Review of Economic Studies, 60(1), 35-52. Retrieved from: https://doi.org/10.2307/2297811

Gomułka, S. (2009). Mechanism and sources of world economic growth. Poznań University of Economics Review, 9, 39-56.

Gori, L., \& Sodini, M. (2019). A contribution to the theory of fertility and economic development. Macroeconomic Dynamics, 1-23. Retrieved March 10, 2020 from https://doi.org/10.1017/S1365100519000415

Grossman, G., \& Helpman, E. (1991). Innovation and growth in the global economy. Cambridge, MA: MIT Press.

Hagemann, H. (2009). Solow's 1956 contribution in the context of the Harrod-Domar model. History of Political Economy, 41, 67-87.

Halsmayer, V., \& Hoover, K. D. (2016). Solow's Harrod: Transforming macroeconomic dynamics into a model of long-run growth. The European Journal of the History of Economic Thought, 23(4), 561-596.

Harrod, R. F. (1939). An essay in dynamic theory. The Economic Journal, 49(193), 14-33.

Howitt, P., \& Weil, D. N. (2010). Economic growth. In S. N. Durlauf \& L. E. Blume (Eds.), Economic growth (pp. 38-50). London: Palgrave Macmillan.

Ippoliti, E. (2017). Scientific discovery reloaded. Topoi. Retrieved from https://doi. org/10.1007/s11245-017-9531-3

Joffe, M. (2017). Evidence and the micro-foundations of economic growth. Economics and Business Review, 17(3), 52-79.

Kawalec, P., (2018a). Metodologia integralna: studium dynamiki wiedzy naukowej. Lublin: Wydawnictwo KUL.

Kawalec, P. (2018b). Transformations in breakthrough research: The emergence of miRNAs as a research routine in molecular biology. Open Information Science, 2(1), 127-146.

Kawalec, P. (2020). Cognitive dynamics of research routines: Case study of MicroRNA. In R. Giovagnoli \& R. Lowe (Eds.), The logic of social practices (pp. 133-152). Cham: Springer International Publishing.

Lucas, R. E. (1988). On the mechanics of economic development. Journal of Monetary Economics, 22(1), 3-42.

Maddison, A. (2001). The world economy: A millennial perspective. Paris: OECD.

Malthus, T. R. (1798). An essay on the principle of population. London: Johnson.

Okada, K. (2020). Dynamic analysis of demographic change and human capital accumulation in an R\&D-based growth model. Journal of Economics. Retrieved from https://doi.org/10.1007/s00712-020-00692-x

O'Rourke, K. H., Rahman, A., \& Taylor, A. M. (2019). Trade, technology, and the great Divergence (Working Paper No. 25741). Cambridge, MA: National Bureau of Economic Research. 
Pelloni, A., Stengos, T., \& Valenti, F. (2019). The non-linearity in the relationship between human capital and growth. In A. Bucci, K. Prettner, \& A. Prskawetz (Eds.), Human capital and economic growth: The impact of health, education and demographic change (pp. 3-26). Cham: Springer International Publishing.

Perrin, F. (2011). Unified Growth Theory: An insight. Historical Social Research / Historische Sozialforschung, 36(3), 362-372.

Romer, P. M. (1986). Increasing returns and long-run growth. Journal of Political Economy, 94(5), 1002-1037.

Romer, P. M. (1990). Endogenous technological change. Journal of Political Economy, 98(5, Part 2), S71-S102.

Snowdon, B., \& Galor, O. (2008). Towards a unified theory of economic growth. World Economics, 9(2), 97-151.

Solow, R. M. (1956). A contribution to the theory of economic growth. The Quarterly Journal of Economics, 70(1), 65-94.

Solow, R. M. (1957). Technical change and the aggregate production function. The Review of Economics and Statistics, 39(3), 312-320.

Spear, S. E., \& Young, W. (2017). Macroeconomic dynamics survey: Endogenous growth theory and models: The "First Wave", 1952-1973. Macroeconomic Dynamics, 1-26. Swan, T. W. (1956). Economic growth and capital accumulation. Economic Record, $32(2), 334-361$. 